\title{
Collagen type II expression in the intervertebral disc after cigarette smoke exposure: An experimental study using wistar rats \\ Farid Murfuadz ${ }^{\mathrm{a}}$, Heru Rahmadhany ${ }^{\mathrm{b}}$, Husnul Fuad Albar ${ }^{\mathrm{b}}$

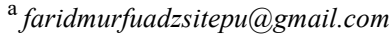 \\ ${ }^{a}$ Resident of Orthopaedics and Traumatology, Faculty of Medicine, Universitas Sumatera Utara / RSUP H. Adam Malik, Medan \\ ${ }^{b}$ Consultant of Orthopaedics and Traumatology, Faculty of Medicine, Universitas Sumatera Utara / RSUP H. Adam Malik, Medan
}

\section{Abstract}

Background: Low back pain is often caused by the degeneration of intervertebral disc. Cigarette smoking has been found to be related to the disturbance of intervertebral disc function. This study aimed to evaluate the type II collagen expression in the intervertebral disc after cigarette smoke exposure with an experimental study using male wistar rats.

Methods: This research was an experimental study using post-test only group design conducted in January to April 2021. The samples were 21 male adult wistar rats which were divided into 3 groups. There were 3 rats included in the control group (without exposure), 9 rats included in the Group I (4 weeks of exposure), and 9 rats included in the Group II (8 weeks of exposure). Immunohistochemical (IHC) staining and microscopic observation were done to the vertebral specimen to evaluate the type II collagen expression. There were 2 observers whose observation results were compared and tested using kappa reliability test. Data were analysed using chi square test.

Results: There were a total of 21 samples included in this study. All samples from the control group showed strong staining, while moderate staining was found dominant $(77.8 \%)$ in the group I, and weak staining was dominant $(55.6 \%)$ in the group II. Kappa reliability test showed $\mathrm{k}=0,62$ $(\mathrm{p}<0,05)$ and was interpreted as substantial agreement. Chi square analysis showed there was a significant difference between the IHC staining results of the control group and group II $(\mathrm{p}=0.002)$.

Conclusion: There was a significant decrease of type II collagen expression in the intervertebral disc of male adult wistar rats which were exposed to cigarette smoke for 2 months

Keywords: Cigarette, Intervertebral Disc, Type II Collagen

\section{Background}

Low back pain has been a health problem for $50 \%-80 \%$ of adult population during their lifetime. ${ }^{1}$ This disorder is generally more prevalent among women. ${ }^{2}$ The prevalence in Indonesia has been reported to range from $7.6 \%-37 \%$ with a peak prevalence at the age of $25-60$ years old. ${ }^{3}$

Although rarely associated with mortality, low back pain is one of the major causes of morbidity in the world. This disorder has become one of the top ten causes of decreased quality of life based on disability adjusted life years (DALY). ${ }^{4}$

Disc disorder, which is generally caused by degeneration, is the main cause of low back pain. ${ }^{5}$ In the United States, it has been found that approximately $20 \%$ of adults are active smokers and it also has been found that 
smoking can interfere with the function of the spinal disc. It has been reported that disc degeneration is found to be more severe on MRI imaging in smokers than in non-smokers. ${ }^{6}$

This study aimed to evaluate the expression of type II collagen in the vertebral disc after exposure to cigarette smoke using an experimental test on a rat model.

\section{Methods}

This study is an experimental study using a post-test only control group design. This research was conducted from January 2021 - April 2021 at the Integrated Laboratory of the Faculty of Pharmacy, University of North Sumatra (USU), the Department of Anatomical Pathology, Faculty of Medicine, USU, and the Department of Anatomical Pathology, H Adam Malik General Hospital Medan. This study has received ethical approval from the Ethics Commission of the Faculty of Mathematics and Natural Sciences (FMIPA), USU.

The population used in this study were adult male wistar rats weighing 150-200 grams obtained from the Integrated Laboratory of the Faculty of Pharmacy, USU. Samples were taken based on the inclusion criteria. The inclusion criteria in this study were male and healthy wistar rats, which were not feverish $\left(38.3-39.4^{0} \mathrm{C}\right)$, weighed 150-200 grams, and were about 2-3 months old. The dropout criteria in this study were all rats that died during the study. The samples included in this study were 21 samples which were divided into 3 groups: 1) Controls were 3 samples; 2) Group I that received exposure to cigarette smoke for 4 weeks were 9 samples; and 3) Group II that received exposure for 8 weeks were 9 samples.

Rats in the exposure group were given cigarette smoke passively with a duration of 4 minutes and then were given free air ventilation for 5 minutes using a filter cigarette which contained $16 \mathrm{mg}$ of tar and 1.8 nicotine. The number of cigarettes given were 20 cigarettes per day for the duration specified for the group.

After the exposure time was over, euthanasia was performed on the sample, then the 11th, 12th thoracic vertebrae, and the 1st lumbar vertebrae were taken, and then were separated by means of disarticulating procedure of 2 facet joints and 1 intervertebral joint with a scalpel to obtain the vertebrae. Histological preparations were then made from the specimens obtained and stained with IHC.

Histopathological observations were carried out by two observers. Assessment of the findings was carried out to determine the staining results indicating the expression of type II collagen. Staining results were assessed based on the components of intensity and area of staining. The findings of the two observers were then tested for reliability using the kappa test

Analysis of the relationship between the exposure to cigarette smoke and the expression of type II collagen based on the histopathological staining results was conducted the chi square test. The test was carried out on the control group - Group I and the control group - Group II.

\section{Results}

There were 21 male wistar rats included as the samples in this study and were divided into 3 groups. Observation of the results of IHC staining on the sample was carried out by two observers with the kappa test showing the value of $\mathrm{k}=0.62(\mathrm{p}<0.05)$, which was interpreted as a substantial agreement. Type II collagen expression based on staining observations is presented in Table 1. below: 
Table 1. Type II Collagen Expression Based on IHC Staining Results

\begin{tabular}{cccc}
\hline \multirow{2}{*}{ Group } & \multicolumn{3}{c}{ Staining Results } \\
\cline { 2 - 4 } & Weak & Moderate & Strong \\
\hline Control $(\mathrm{n}=3)$ & $0(0 \%)$ & $0(0 \%)$ & $3(100 \%)$ \\
Group I $(\mathrm{n}=9)$ & $0(0 \%)$ & $7(77,8 \%)$ & $2(22,2 \%)$ \\
Group II $(\mathrm{n}=$ & $5(55,6 \%)$ & $4(44,4 \%)$ & $0(0 \%)$ \\
$9)$ & & & \\
\hline
\end{tabular}

From the results of the analysis on the expression of type II collagen, it can deducted that in the group with exposure to cigarette smoke for 1 month, the majority were with moderate expression (77.8\%) while in the group with exposure to cigarette smoke for 2 months, the majority were weak expression (55.6\%).

Table 2. Differences Between Groups Based on IHC Staining Results

\begin{tabular}{ll}
\hline Staining Results Comparison & p Value \\
\hline Control - Group I & 0,18 \\
Control - Group II & 0,002 \\
\hline
\end{tabular}

Table 2. presented above shows that there is a statistically significant difference between the staining results in the control and group II. Based on this finding, it is interpreted that there is a significant relationship between the exposure to cigarette smoke for 8 weeks and a decrease in the expression of type II collagen in the intervertebral discs of male wistar rats. The description of the histopathological observations in this study is presented in Figure $1-3$ below. 


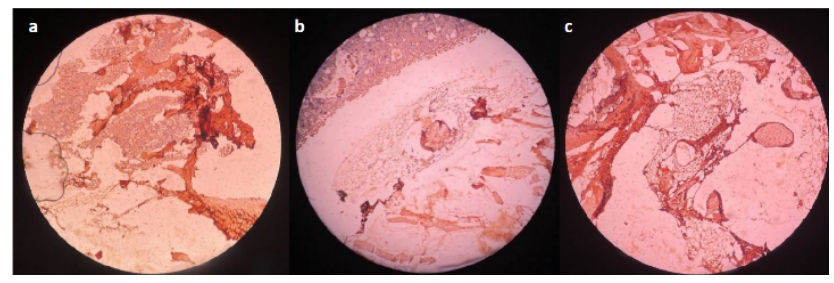

Figure 1. Staining Results on the Control Group

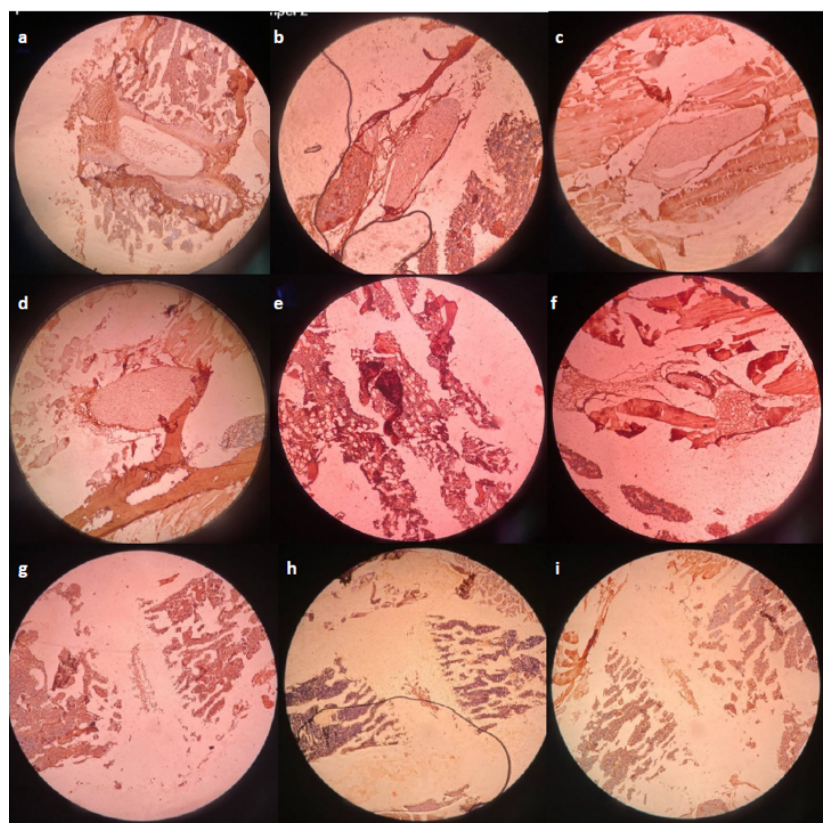

Figure 2. Staining Results on Group I 


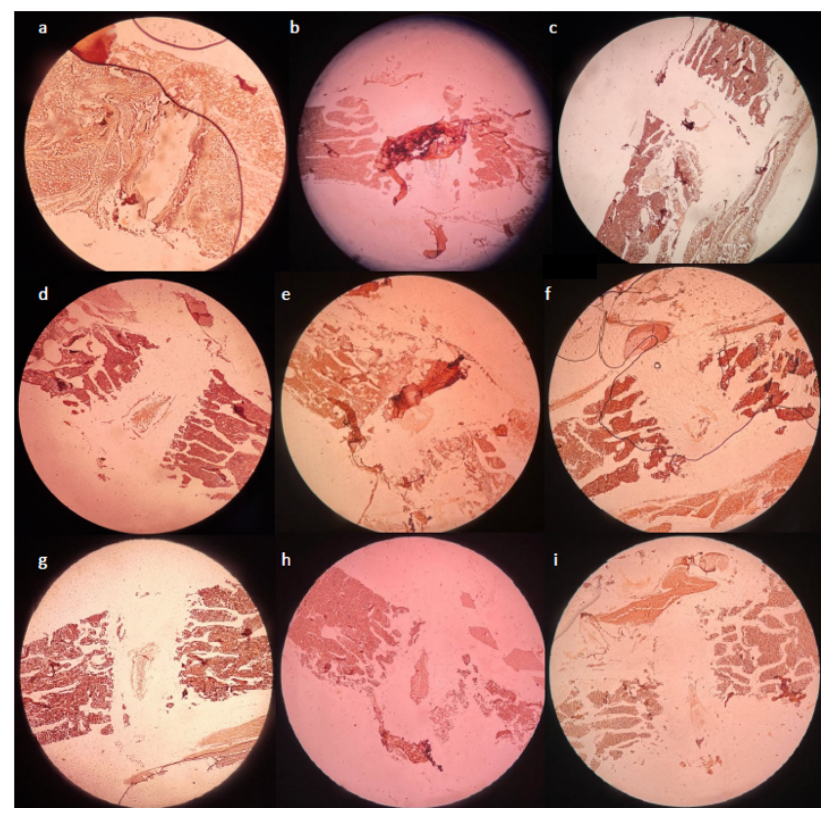

Figure 3. Staining Results on Group II

\section{Discussion}

From the results of the analysis, there was no difference in changes in the expression of type II collagen in the vertebral disc, particularly in the nucleus pulposus after cigarette smoke exposure using an experimental test on rat models exposed to cigarette smoke for 1 month when compared to the control, which obtained the $p$ value $=0.18$, but there was a significant difference between group II or those exposed to cigarette smoke for 2 months with the control, which obtained the $\mathrm{p}$ value $=0.002$.

The findings obtained from this study are in line with previous studies based on the histopathological results by Oda $\mathrm{H}$ et al where the structure of the nucleus pulposus is still clearly visible when exposed for 1 month compared to 2 months exposure. ${ }^{7}$

The main function of the vertebral disc is very dependent on the composition, the organization of the extracellular matrix allowing it to sustain mechanical responses. The main known compositions are type I and II collagen which constitute $70 \%$ and $20 \%$ of the weight of the annulus and nucleus, respectively. Aggrecan is the main proteoglycan component in the disc which has a function to maintain the osmotic pressure of the disc. Apart from that, there are also minor components such as type III, V, VI, IX, X, XI, XII and XIV collagens; Other proteoglycans such as lumican, biglican, decorin, fibromodulin and other glycoproteins such as fibronectin and amyloid. Type IX collagen is also important in maintaining the integrity between collagen fibers. ${ }^{3}$ Garnero et al. stated that the destruction of spinal joints is mainly due to the increased degradation of type II collagen. ${ }^{8}$ That is also consistent with this study where the nucleus pulposus of the rats were found with decreased expression by the immunohistochemical method specifically in the group that were exposed for 2 months.

This refers to the composition of cigarettes that depleted nutrients to the disc and accelerate the degeneration 
process and that cigarette could increase the levels of carbon monoxide which is known to bind more easily to haemoglobin when compared to oxygen. In addition, the state of tissue hypoxia due to smoking also induces the production of inflammatory cytokines which could cause disruption of cellular activity which could lead to increased catabolic activity and cause degeneration of the intervertebral disc.

\section{Conclusion}

There was a significant difference in the expression of type II collagen between the control group and group II that was exposed to cigarette smoke for 2 months, but not between the control group and the group that was exposed to cigarette smoke for 1 month.

\section{References}

1. Fatoye F, Gebrye T, Odeyemi I: Real world incidence and prevalence of low back pain using routinely collected data. Rheumatology international 2019, Page 619

2. Ramdas J, Jella V: Prevalence and risk factors of low back pain. International Journal of Advances in Medicine, India 2018, Page 1

3. Gaya LL: Pengaruh Aktivitas Olahraga Kebiasaan Merokok dan Frekuensi Duduk Statis Dengan Kejadian Low Back Pain, Fakultas Kedokteran Universitas Lampung 2015, Page: 186-187

4. Meucci R, Fassa A, Faria N. Prevalence of chronic low back pain: a systematic review. Rev Saude Publica. 2015;49:1. Available from: https ://www.ncbi .nlm.nih.gov/pmc/articles/PMC4603263/

5. Kim HS, Wu PH, Jang IT: Lumbar Degenerative Disease Part 1 Anatomy and Pathophysiology of Intervertebral Discogenic Pain and Radiofrequency Ablation of Basivertebral and Sinuvertebral Nerve Treatment for Chronic Discogenic Back Pain: A Prospective Case Series and Review of Literature, International Journal of Molecular Sciences 2020

6. Elmasry S, Asfour S, Vaccari JPR, Travascio F: Effects of tobacco smoking on the degeneration of the intervertebral disc a finite element study, Plos One, Canada 2015

7. Oda H, Matsuzaki H, Tokuhashi Y, Wakabayashi K, Uematsu Y, Iwahashi M: Degeneration of intervertebral disc due to smoking experimental assessment in a rat smoking model. Journal of orthopaedic science. Tokyo 2003. Page: 138-139

8. Garnero P, Rendu ES, Arlot M, Christiansen C, Delmas PD: Association between spine disc degeneration and type II collagen degradation in postmenopausal women. American college of rheumatology. 2004 